\title{
A influência do conhecimento na atitude frente à vacina contra o Papilomavírus Humano: ensaio clínico randomizado
}

\author{
The influence of the knowledge towards the vaccine against Human \\ Papillomavirus: a randomized clinical trial
}

Rodrigo Guilherme Varotti Pereira¹, José Lúcio Martins Machado², Valéria Menezes Machado³, Tangará Jorge Mutran³, Luiz Silva dos Santos ${ }^{3}$, Emerson Oliveira ${ }^{4}$, César Eduardo Fernandes ${ }^{4}$

1Universidade Cidade de São Paulo (UNICID) - São Paulo (SP), Brasil.

2Universidade Municipal de São Caetano do Sul (USCS) - São Caetano do Sul, (SP), Brasil.

3Universidade de São Paulo (USP) - São Paulo (SP), Brasil.

${ }^{4}$ Faculdade de Medicina do ABC (FMABC) - Santo André (SP), Brasil.

DOI: http://dx.doi.org/10.7322/abcshs.v41i2.873

\begin{abstract}
RESUMO
Introdução: O Papilomavírus humano (HPV) está associado às doenças sexualmente transmissíveis (DSTs) e à carcinogênese do trato genital inferior. Objetivo: Avaliar o conhecimento prévio e o papel da ação educativa sobre a atitude em relação à vacinação para Papilomavírus Humano (HPV). Métodos: Estudo de intervenção, tipo ensaio-clínico randomizado com 200 mulheres de 18 a 30 anos, divididas em dois grupos submetidos a um questionário para avaliar o conhecimento prévio sobre o HPV e sua vacina, e a atitude para a vacinação, tendo um dos grupos recebido intervenção por meio de ação educativa. Resultados: A atitude frente à vacina contra o HPV foi diferente no grupo que recebeu a ação educativa, com $37 \%$ de atitudes pessoais adequadas $(p=0,044)$ e $49 \%$ na atitude de transferência adequada para uma futura filha $(p=0,021)$. Conclusão: $O$ conhecimento prévio sobre o HPV e sua vacina é escasso, insuficiente e por vezes equivocado. Por meio da comparação da atitude dos diferentes grupos verificou-se que a ação educativa exerce papel determinante na atitude correta das mulheres para a vacina contra o HPV e modifica os condicionantes à sua adesão.
\end{abstract}

Palavras-chave: conhecimento; atitude; vacinação; vacinas contra Papillomavirus.

\begin{abstract}
Introduction: The human papillomavirus (HPV) is associated with sexually transmitted diseases (STD) and the lower genital tract carcinogenesis. Objective: To evaluate the previous knowledge and the function of educational action towards the reaction regarding the vaccine for Human Papilomavírus (HPV). Methods: Intervention study, like randomized clinical trial, considering 200 18-30 year-old women, divided in two groups submitted to a questionnaire to evaluate the previous knowledge about HPV and its vaccine, and the attitude for the vaccination, with one of the groups receiving intervention through educational action. Results: The attitude towards the vaccine against HPV was different in the group that received the educational action, with $37 \%$ of proper personal attitude $(p=0,044)$ and $49 \%$ in the transference to a likely daughter $(p=0,021)$. Conclusion: The previous knowledge about HPV and its vaccine is scarce, insufficient and sometimes mistaken. Through the comparison of attitude between different groups it was confirmed that the educational action does a determinant role to the correct women's attitude to the vaccine against HPV and modifies the conditions of its accession.
\end{abstract}

Keywords: knowledge; attitude; vaccination; Papillomavirus vaccines. 


\section{INTRODUÇÃO}

Evidências epidemiológicas e laboratoriais têm demonstrado que o Papilomavírus humano (HPV) está associado às doenças sexualmente transmissíveis (DSTs) e à carcinogênese do trato genital inferior ${ }^{1,2}$. Trata-se de um vírus DNA com cerca de 200 tipos já identificados dos quais 40 podem infectar o trato genital. A maior parte dos HPVs são transientes e assintomáticos, contudo, estima-se que $10 \%$ das mulheres infectadas com os tipos considerados de alto risco tornam-se portadoras crônicas e portanto com risco de desenvolvimento do câncer de colo uterino ${ }^{3}$. Os tipos de baixo potencial oncogênico, como 6 e 11, desenvolvem verrugas ou condilomas acuminados e são associados a $90 \%$ destas manifestações ${ }^{3}$. Por outro lado, os ditos de alto potencial oncogênico, como 16 e 18, podem associar-se ao carcinoma de colo do útero, vagina, vulva e ânus ${ }^{2}$, e estão presentes em $70 \%$ desses casos ${ }^{3}$.

Assim, a identificação do HPV é necessária com o objetivo de diminuir a prevalência do câncer de colo uterino ${ }^{4}$ considerando que, em todo o mundo, aproximadamente 5,5 milhões de pessoas desenvolvem a infecção genital pelo HPV a cada ano ${ }^{4}$.

A prevalência da infecção em mulheres com menos de 30 anos chega a ser superior a $30 \%$ e declina para níveis de 4 a $5 \%$ em mulheres com mais de 45 anos $^{5}$. No Brasil, a prevalência global de HPV é de $17,1 \%$, decrescendo com a idade, ou seja em mulheres abaixo dos 20 anos foi de $33,9 \%$ e naquelas acima de 41 anos foi de $11 \%{ }^{6}$.

A imunização como medida de prevenção primária tem demonstrado ser uma das intervenções de maior sucesso e melhor custo-efetividade. Esta constatação tem encorajado especialistas e autoridades na adoção de uma política de vacinação em massa contra o HPV. A vacina terapêutica, ainda em estudo, seria utilizada para induzir a regressão de lesões pré-neoplásicas ou remissão do carcinoma avançado de colo uterino ${ }^{7}$.

Os estudos mais recentes demonstram que a vacina feita por meio de estrutura protéica com capsídio viral induz altos títulos de anticorpos neutralizantes e permite um tempo de proteção ao redor de $5 \operatorname{anos}^{8,9}$. Ademais, alguns autores acreditam na possibilidade de que a imunização seja permanente e que três doses sejam suficientes para a prevenção por toda a vida. Este raciocínio tem sido motivo para que muitos estudiosos cobrem das autoridades maior comprometimento para a implantação e operacionalização da vacina contra o HPV no calendário vacinal utilizado pela rede de saúde ${ }^{10,11}$.

A literatura demonstrou alguns problemas na adesão dos pacientes à vacina contra o HPV e, portanto, o sucesso desta medida de imunização, esbarra em alguns fatores, como: o conhecimento sobre as implicações clínicas da infecção crônica do HPV, barreiras culturais na relação com doenças sexualmente transmissíveis, cobertura da rede de saúde, distribuição da vacina e armazenagem, aceitabilidade $^{3}$ e mudanças dos hábitos sexuais ou preventivos para outras doenças sexualmente transmissíveis (preocupação destacada pelos pais quando da autorização da vacinação para seus filhos) ${ }^{12}$.
Ao considerar a prevalência de HPV e seus desdobramentos, este estudo aborda um tema atual e de grande relevância para a Saúde Pública. Nossos objetivos foram identificar e qualificar o conhecimento sobre o HPV e sua vacina, avaliar a influência deste sobre a atitude de adesão e seus eventuais condicionantes, e, finalmente, esclarecer o efeito real de uma intervenção educativa na aplicabilidade da vacinação contra o HPV.

\section{MÉTODOS}

Como estudo de intervenção tipo ensaio clínico controlado randomizado, utilizando como instrumento de intervenção a ação educativa aplicada, esta presente pesquisa teve o tamanho da sua amostra calculada pelo software EpiInfo 3.3.2, considerando o maior tamanho da amostra, a fim de atender a validação de todas as hipóteses geradas. Assumiu-se erro alfa de $5 \%$ e intervalo de confiança de 95\% (IC95\%), erro beta de $20 \%$ e poder da amostra de $80 \%$ (20\% de diferença desejada entre os grupos). Dessa forma, a amostra calculada foi de 200 mulheres. Posteriormente, utilizamos o software Excel na geração de tabela de números randômicos.

Os sujeitos foram selecionados entre mulheres do Estado de São Paulo, no período de 2008 a 2010, por meio da realização de nove campanhas multidisciplinares de promoção à saúde abertas ao público geral. Essas campanhas de ampla abordagem, em que diversas ações de saúde foram aplicadas, ocorreram nas comunidades dos bairros paulistanos da Vila Maria, Pari, e Jardim dos Eucaliptos, na Universidade Cidade de São Paulo e entorno, e na cidade de Mairiporã.

Como critérios de inclusão, foram considerados: sexo feminino, idade entre 18 e 30 anos e vida sexual ativa. Por sua vez, os critérios de não inclusão foram: a existência de condições físicas ou psicológicas que impedissem a participante voluntária de responder ao questionário e/ou a colheita de material vaginal por meio do exame ginecológico.

Após a assinatura do Termo de Consentimento Livre e Esclarecido (TCLE), as voluntárias foram randomizadas em dois grupos: G1 e G2.

Ambos os grupos se submeteram ao questionário estruturado, validado, e pré-testado, do tipo Conhecimento, atitude e prática $(\mathrm{CAP})^{13}$; porém, sem a prática, uma vez que, quando da coleta de dados, a vacinação não estava implantada como política pública. Logo, não foi possível avaliar esse quesito.

Para as mulheres selecionadas no grupo G1, foi interposta entre o questionário de conhecimento e o de atitude, a intervenção por meio de palestra individual com a aplicação de um programa educativo interativo contendo material sobre o HPV e sua vacina. A interação com a participante, orientada pelo agir comunicativo, para a formação de sua tomada de decisão sobre a vacina contra o HPV corroborou para que, no decorrer da palestra, fossem esclarecidas eventuais dúvidas sobre o tema em tela. 
Como coleta de informações adicionais, para fins da continuidade futura do estudo e seguimento das participantes, após a aplicação do questionário, todas as mulheres (do G1 e do G2) foram convidadas ao exame ginecológico e à coleta de material vaginal, que foi obtida por raspado, com escova, do colo do útero e das paredes vaginais, expostas através do espéculo ginecológico. O material a fresco foi colocado em tubos de eppendorf, com solução tamponada e congelado a $18^{\circ} \mathrm{C}$ negativos, para posterior extração do DNA-HPV para identificação dos tipos de HPV por meio da Reação de Cadeia da Polimerase (PCR).

Caso apresentasse infecções genitais identificáveis à macroscopia, a participante era orientada ao tratamento e seguimento em ambulatório especializado, conveniado ou público, conforme sua escolha.

Para fins éticos, as mulheres do grupo G2 participaram das palestras educativas depois de concluídas as etapas da coleta de dados do estudo.

Para caracterizar as mulheres entrevistadas, foram elencadas as variáveis: idade, raça/cor, estado civil, idade da primeira relação sexual, tipo de serviço de saúde mais utilizado, renda familiar, religião, hábitos e vícios, número de parceiros sexuais no último ano, método contraceptivo, hábito de coleta de colpocitologia oncológica e antecedentes obstétricos.

No intuito de responder aos objetivos da pesquisa, foram analisados quatro elementos: conhecimento prévio sobre o HPV, conhecimento prévio sobre a vacina contra o HPV, atitude pessoal e atitude de transferência para uma suposta filha para a vacina contra o HPV, detalhadas a seguir.

O conhecimento prévio sobre o HPV foi qualificado como adequado quando a participante, já havia ouvido falar sobre o vírus e o associava como doença sexualmente transmissível, relacionado ao câncer de colo uterino ou à verruga genital. Quanto ao conhecimento sobre a vacina contra o HPV, qualificamos como adequado quando a voluntária já tinha ouvido falar de sua existência e/ou possibilidade de utilização no Brasil e sua utilidade para fins exclusivos de prevenção primária.

Também foi qualificado o Conhecimento Prévio Pleno, sendo considerado adequado quando da presença dos conhecimentos prévios à participação na pesquisa, adequados tanto ao Papilomavírus Humano e quanto à sua vacina.

A atitude pessoal e de transferência para uma provável filha frente à vacina contra o HPV foi qualificada como adequada quando da adesão incondicional à vacina, sendo também elencados os condicionantes a fim de identificar o comportamento das participantes.

Ao comparar os dois grupos randomizados de participantes quanto ao conhecimento prévio apresentou-se o perfil desse conhecimento e sua influência sobre a atitude. Ao avaliar a atitude nos dois diferentes grupos, procurou-se verificar se a intervenção, dada pela ação educativa, foi ou não agente modificador e, portanto, influente na adesão.

Para análise dos resultados utilizou-se a estatística descritiva exploratória e inferencial por meio do teste $\chi^{2}$. Foi adotado um nível de significância de 5\% e um IC95\%.
Os resultados foram analisados e comparados com o auxílio dos programas de análise estatística EpiInfo Versão 3.5.3 e IBM SPSS Statistics Versão 19.

O trabalho foi previamente submetido e aprovado pelos Comitês de Ética em Pesquisa da Universidade Cidade de São Paulo (número 13281691) e do Instituto de Assistência ao Servidor Público Estadual (IAMSPE) - número 044/2009. Posteriormente, atendendo aos ditames ordinários o ensaio clínico foi devidamente registrado no site ClinicalTrials.gov, sob o número: NCT01043341.

\section{RESULTADOS}

A média de idade foi de 25 anos, tendo a maioria das mulheres definindo-se como pardas ou negras (52\%), solteiras (50\%), católicas (47\%), com trabalho remunerado (63,5\%), com renda familiar de até R\$2.000,00 (84,5\%) e usuárias dos sistemas públicos de saúde (76\%).

Os hábitos pessoais e sexuais, cuidados com a saúde e antecedentes obstétricos, indicaram como idade média de inicio da vida sexual os 16 anos, com extremos de 11 e 25 anos. Além disso, havia uma média de dois parceiros sexuais ao ano, e a maioria das participantes, utilizava como método contraceptivo o anticoncepcional hormonal oral ou injetável (55,5\%). Digno de nota é que o uso regular de preservativos foi de $34,5 \%$ e $13 \%$ das voluntárias não costumavam ou nunca fizeram a coleta do exame de Papanicolaou.

Em relação ao tabagismo, 29,5\% das participantes referiram fazer uso regular ou pregresso, com uma média de nove cigarros consumidos diariamente. $\mathrm{Na}$ avaliação do uso de drogas ilícitas e bebidas alcóolicas, $1 \%$ referiu consumo esporádico de entorpecentes, enquanto $61 \%$ referiram fazer uso de álcool frequentemente ou eventualmente.

No tocante ao contato prévio com o HPV ou a existência de sua expressão clínica, $93 \%$ das participantes referiram não terem tido qualquer indício do vírus, 5,5\% afirmaram já terem sido diagnosticadas como portadoras enquanto $1,5 \%$ informaram estar em tratamento no momento da pesquisa.

Questionadas sobre o conhecimento prévio sobre o HPV, $77 \%$ das entrevistadas referiram já ter ouvido falar do vírus, tendo como fonte dessa informação, em sua maioria, os meios de comunicação $(65,2 \%)$, entre estes a TV, o rádio e as revistas. Destaca-se que $28,3 \%$ das participantes referiram ter ouvido falar do HPV por seu médico e 29,6\% em palestras ou ações educativas prévias (Figura 1).

Das entrevistadas, $52 \%$ associavam corretamente o vírus como causador de verruga genital ou câncer enquanto 36\% entendiam sua infecção como uma doença sexualmente transmissível (DST).

Dessa forma, ao considerar o conhecimento prévio do HPV correto como aquele onde a voluntária tem conhecimento da existência do vírus e o relaciona a uma DST, ao câncer de colo e ao condiloma genital, observamos que 65\% das participantes apresentaram-se nesta situação, sem haver diferenças significantes 
na expressão desse conhecimento entre os grupos do estudo $(\mathrm{p}=0,234)$ (Tabela 1$)$.

Interrogadas sobre o conhecimento prévio sobre a vacina contra o HPV, 68,5\% das mulheres desconheciam a existência desse recurso de prevenção primária.

Das participantes que já conheciam a existência da vacina contra o HPV, $46 \%$ afirmaram ter obtido essa informação por meio da TV ou Rádio, enquanto 17,5\% obtiveram esse conhecimento de conversas com amigas e outras $17,5 \%$ por meio de seu médico (Figura 1).

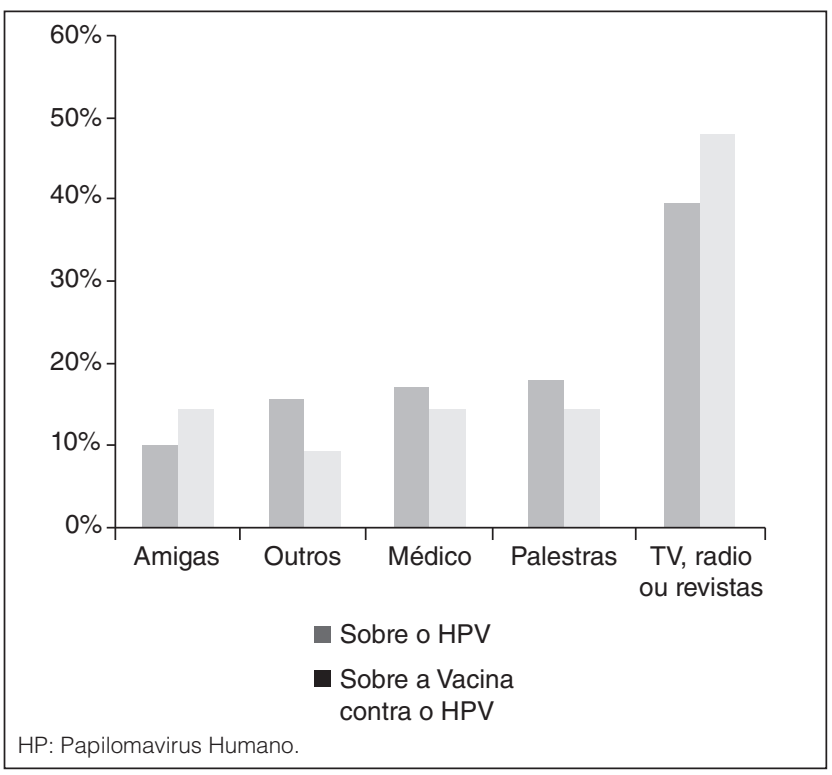

Figura 1: Fontes de conhecimento sobre o Papilomavirus Humano e sobre a vacina contra o Papilomavirus Humano (em \%) em mulheres de 18 a 30 anos do estado de São Paulo, entre os anos de 2008 a 2010

Tabela 1: Conhecimento Prévio sobre o Papilomavirus Humano e Atitude para com a vacina contra o Papilomavirus Humano em mulheres de 18 a 30 anos do estado de São Paulo entre os anos de 2008 a 2010

\begin{tabular}{|c|c|c|c|}
\hline & $\begin{array}{c}\text { Com } \\
\text { Intervenção }\end{array}$ & $\begin{array}{c}\text { Sem } \\
\text { Intervenção }\end{array}$ & Valor p* \\
\hline $\begin{array}{c}\text { Conhecimento } \\
\text { Sobre o HPV }\end{array}$ & & & \\
\hline $\begin{array}{c}\text { Adequado } \\
\text { Inadequado }\end{array}$ & 70 & 61 & 0,234 \\
\hline $\begin{array}{c}\text { Sobre a Vacina } \\
\text { Adequado }\end{array}$ & 30 & 39 & \\
\hline $\begin{array}{c}\text { Contra o HPV } \\
\text { Inadequado }\end{array}$ & 11 & 7 & 0,459 \\
\hline $\begin{array}{c}\text { Atitude } \\
\text { Pessoal }\end{array}$ & 89 & 93 & \\
\hline $\begin{array}{c}\text { Adequado } \\
\text { Inadequado }\end{array}$ & 37 & 23 & 0,044 \\
\hline $\begin{array}{c}\text { De Transferência } \\
\text { Adequado }\end{array}$ & 63 & 77 & \\
\hline Inadequado & 49 & 32 & 0,021 \\
\hline
\end{tabular}

HPV: Papilomavirus Humano; *Teste de Fisher ( $\chi^{2}$ Bicaudal)
Avaliando o conhecimento sobre a utilidade da vacina contra o HPV apenas $28,6 \%$ tinham a informação correta sobre sua ação preventiva, enquanto a maioria $(71,4 \%)$ acreditava que a vacina apresentava fins terapêuticos.

Dessa forma, considerando o conhecimento correto sobre a vacina contra o HPV, qualificado por sua ação exclusivamente preventiva, 9\% das mulheres envolvidas no estudo apresentavam conhecimento correto.

$\mathrm{Na}$ comparação entre os grupos, não foi identificada diferença estatisticamente significante no envolto ao conhecimento correto da vacina contra o HPV $(\mathrm{p}=0,459)$ (Tabela 1$)$.

$\mathrm{Na}$ avaliação do conhecimento prévio pleno sobre o HPV e sua vacina identificamos que $8,5 \%$ das mulheres apresentavam-se conhecedoras da questão e na comparação desse item não houve diferenças $(p=0,613)$.

$\mathrm{Na}$ análise comparativa em relação à atitude para a vacina contra o HPV, o grupo submetido à ação educativa manifestou atitude correta em $37 \%$ das entrevistadas contra $23 \%$ daquelas que não haviam recebido intervenção por meio da ação educativa preliminar. Tal achado apresentou diferença estatística significante $(\mathrm{p}=0,044)$ (Tabela 1$)$.

Os condicionantes quanto à adesão à vacina contra o HPV foram apresentados pelos dois grupos de forma contrastante, sendo que o grupo que não recebeu a ação educativa manifestou maior dependência da recomendação do médico de confiança, com 33,3 contra 20,2\% das mulheres do grupo sob intervenção. Da mesma forma, as mulheres desse grupo, condicionaram em menor porcentagem $(27,3 \%)$ à obtenção de mais informações em relação ao grupo sem instrução anterior à entrevista (41,4\%) (Figura 2).

Caso a vacina fosse gratuita, o grupo intervenção a receberia em 15,2 versus $2 \%$ no grupo controle (Figura 2 ).

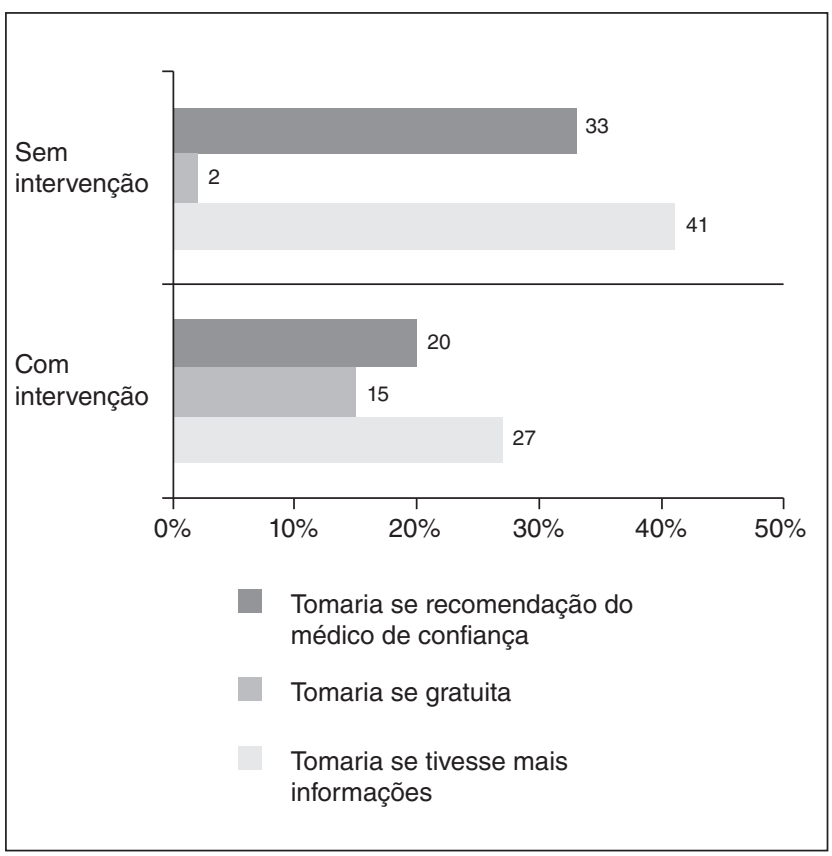

Figura 2: Condicionantes da atitude à adesão para a vacina contra o Papilomavirus Humano das mulheres de 18 a 30 anos do estado de São Paulo de 2008 a 2010 
A atitude de transferência para supostas filhas para com a vacina contra o HPV indicou que apenas 3\% das entrevistadas não permitiriam, pois acreditavam que isso induziria à antecipação do inicio da vida sexual, $40,5 \%$ permitiriam por considerar importante, $44 \%$ informaram que permitiriam desde que obtivessem mais informações, enquanto $12,5 \%$ não souberam responder.

Ao considerar a atitude correta a da concordância incondicional de administração da vacina contra o HPV para as filhas, $49 \%$ do grupo com a ação educativa preliminar mostraram-se favoráveis enquanto apenas $32 \%$ do grupo sem exposição, o que manifestou comportamento significativamente diferente entre os grupos $(\mathrm{p}=0,021)$ (Tabela 1$)$.

Em análise comparativa entre os grupos, aquele submetido à intervenção apresentou maior adesão e menor preocupação com a indução ao inicio da vida sexual ( 4 contra $2 \%$ do outro grupo) além de considerar minoritariamente a condição de adesão às informações sobre a vacina (40 contra $48 \%$ do grupo sem palestra previa) (Figura 3).

Como informação adicional o resultado da análise da presença de HPV nas participantes indicou incidência de 13,5\%.

\section{DISCUSSÃO}

Identificado o perfil demográfico das participantes, e caracterizado como similar com o da população geral brasileira ${ }^{14}$ nos aspectos socioculturais e econômicos, podemos qualificar a amostra como representante de nossa sociedade majoritária.

Uma vez conhecedores de seus hábitos sexuais e reprodutivos, notamos a exposição das mulheres a diversos fatores de risco para as doenças do trato genital, o que traz para as medidas de prevenção ainda mais importância no contexto da saúde coletiva.

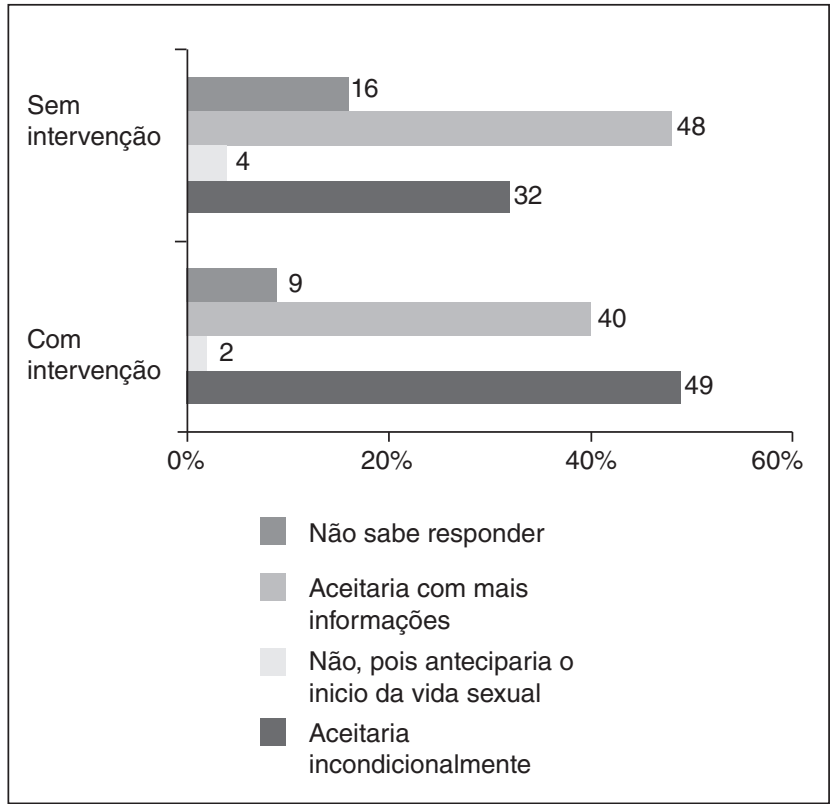

Figura 3: Atitude de transferência para supostas filhas $e$ condicionantes à adesão para a vacina contra o Papilomavirus Humano das mulheres de 18 a 30 anos do estado de São Paulo de 2008 a 2010 diferenciado pelos grupos de participantes
Tais fatores de risco mostram-se evidentes pela exposição cada vez mais precoce ao HPV pelo início da vida sexual, pela exposição de múltiplos parceiros, pelos antecedentes obstétricos e pela alta abstenção aos programas de rastreamento do câncer de colo uterino.

Como usuárias dos provedores públicos de saúde em sua maioria absoluta, podemos com a interpretação dos resultados estabelecerem um perfil das demandas de atividades de promoção de saúde.

O conhecimento prévio sobre o HPV mostrou-se prevalente; porém, ao analisarmos a qualidade desse conhecimento, identificamos conceitos superficiais e equivocados que denominamos no estudo como inadequados. Outros estudos da mesma forma evidenciaram o baixo ou inadequado conhecimento sobre o vírus tanto na comunidade susceptível à infecção ${ }^{15-17}$ quanto em grupos em formação técnica na área da saúde ${ }^{18}$ e nos agentes diretivos das instituições de assistência à saúde ${ }^{19}$.

Quando analisamos o conhecimento sobre a vacina contra o HPV, medida de prevenção disponível e comprovadamente eficaz ${ }^{7,9}$, notamos um absoluto desconhecimento sobre sua existência e sua finalidade exclusivamente profilática. Apesar de não dispormos na literatura nacional de pesquisas que confirmem esse desconhecimento, a literatura internacional também destaca a falta de informações tanto do público alvo da vacinação quanto de suas mães ou responsáveis ${ }^{12,16,20,21}$.

Ao comparar o conhecimento da população estudada sobre o HPV e sua vacina com o apresentado pela literatura, destaca-se a maior qualidade do conhecimento especialmente em países desenvolvidos, fato que se associa comumente à promulgação da educação sexual no plano escolar curricular ${ }^{4,12}$.

$\mathrm{Na}$ busca de justificativas para o desconhecimento ou superficialidade das informações sobre o tema, notamos a similaridade nas fontes de informações tanto em relação ao vírus, quanto à vacina, predominantemente informais, ligados aos meios de comunicação e afastados dos elementos promotores de saúde.

Dessa forma, estando o profissional de saúde distante de sua função de instrutor e provedor de conhecimento, atuante da prática preventiva e não apenas curativa, permite-se à população a busca de respostas em outros meios menos acurados. Quando o profissional de saúde, destacadamente o médico, tem compromisso com o conhecimento sanitário de seus assistidos, o esclarecimento é mais prevalente ${ }^{12,15}$ e a adesão os recursos de saúde mais eficaz.

$\mathrm{O}$ conhecimento incompleto e incorreto sobre o efeito da infecção do HPV, subestima sua influência na qualidade de vida e de saúde e pode influenciar diretamente na busca das mulheres pelos mecanismos de sua prevenção, quer sejam primários ou secundários ${ }^{16}$. Os cuidados com a saúde tornam-se piores na medida em que cresce o desconhecimento das ferramentas para este.

Logo, considerando o conhecimento prévio sobre o HPV e a sua vacina elemento influente sobre a atitude, e tendo os dois grupos similaridade no tocante a isso, podemos julgar que as diferenças expressas sejam resultado da intervenção realizada, ou seja, da ação educativa.

A atitude sobre a vacina do HPV expressa a adesão da paciente frente a este recurso de prevenção, tornando-se primordial para a diminuição da incidência e prevalência do câncer de colo uterino e dos condilomas genitais , $^{7,12,15,17}$. 
$\mathrm{Na}$ atitude das participantes quanto à adesão à vacinação contra o HPV tanto no âmbito pessoal como na transferência relativa à autorização para uma provável ou eventual filha, os grupos manifestaram-se diferentes.

O grupo submetido à intervenção pela ação educativa na instrução sobre o HPV e sua vacina manifestou maior adesão incondicional, enquanto aquele sem intervenção, condicionou a aceitação da vacina à obtenção de mais informações ou à recomendação do médico que lhe assiste, indo ao encontro do que fora apresentado em outros estudos semelhantes ${ }^{16,17}$.

Com isso, evidenciamos que a ação educativa teve papel modificador de conduta, logo podendo ser uma importante ferramenta para o sucesso das campanhas de vacinação contra o HPV em nossa sociedade, fazendo-se aí cumprir o objetivo de reduzir as doenças genitais associadas ao vírus, em especial o carcinoma de colo uterino.

Portanto, baseado no estudo em tela reconhecemos que a informação é chave para o sucesso da aplicação da vacina contra o HPV uma vez que alerta a mulher sobre a importância desta infeção e seu papel na carcinogênese do colo do útero, e que a influência da intervenção por meio de ações educativas atinge melhor atitude e adesão. Assim propomos aos meios promotores de iniciativas sanitárias que dediquem especial atenção aos instrumentos de instrução, para que possamos com políticas de saúde estruturadas reduzir a morbidade e a mortalidade da mulher.

\section{REFERÊNCIAS}

1. Walboomers JM, Jacobs MV, Manos MM, Bosh FX, Kummer JA, Shah $\mathrm{KV}$, et al. Human papillomavirus is a necessary cause of invasive cervical cancer world wide. J Pathol. 1999;189(1):12-9. http://dx.doi.org/10.1002/(SICI)1096-9896(199909)189:1 1212::AIDPATH431 33.0.CO;2-F

2. Syrjänen KJ, Syrjänen SM. Papillomavirus infections in human pathology. Chichester: Wiley; 2000; p.615.

3. Watts LA, Joseph N, Wallace M, Rauh-Hain J, Muzikansky A, Growdon W, et al. HPV vaccine: a comparision of attitudes and behavioral perpestives between latino and non-latino women. Gynecol Oncol. 2009;112(3):577-82. http://dx.doi.org/10.1016/j.ygyno.2008.12.010

4. Dursun P, Altuntas B, Kusku E, Ayhan A. Women's knowledge about human papillomavirus and their acceptance of HPV vaccine. Aust N Z J Obstet Gynaecol. 2009;49(2):202-206. http://dx.doi.org/10.1111/j.1479-828X.2009.00947.x

5. Ratmam S, Franco EL, Ferenczy A. Human Papillomavirus testing for primary screening of cervical cancer precursors. Cancer Epidemiol Biomarkers Prev. 2000;9(9):945-51.

6. Longatto-Filho A, Erzen M, Branca M, Roteli-Martins C, Naud P, Derchain SF, et al. Human papillomavirus testing as an optional screening tool in low-resource settings of Latin America: experience from the Latin American Screening study. Int J Gynecol Cancer. 2006;16(3):955-62. http://dx.doi.org/10.1111/j.1525-1438.2006.00582.x

7. Franco EL, Harper DM. Vaccination against human papillomavirus infection: a new paradigm in cervical cancer control. Vaccine. 2005;23(17-18):2388-94

http://dx.doi.org/10.1016/j.vaccine.2005.01.016

8. Schiller JT, Lowy DR. Perpectives on HPV Virurs-Like particle vaccine efficacy. In: Monsonego J. Emerging issues on HPV infections. Karger; 2006; p.217-26.

9. Pan American Health Organization (PAHO) [Internet]. Important characteristics of profhylatic HPV vaccines for the prevention of cervical cancer. Disponível em: http://www.paho.org/english/ad/ fch/im/HumanPapillomaVirus.htm. Acesso em: 4 set. 2015

10. World Health Organization (WHO). [Internet]. GIVS: Global Imunization vision and strategy 2006-2015. WHO/UNICEF; Disponível em: http://passthrough.fw- notify.net/download/013013/ http://apps.who.int/iris/bitstream/10665/69146/1/WHO_IVB_05.05. pdf. Acesso em: 03 set. 2015

11. Ishibashi KL, Koopmans J, Curlin FA, Ross LF. Paeditricians attitudes and practices towards HPV vaccination. Acta Paediatr. 2008;97(11):1550-56. http://dx.doi.org/10.1111/j.1651-2227.2008.00958.x
12. Hoglund AT, Tyden T, Hannerforns AK, Larsson M. Knowledge of humans papillomavirus and attitudes to vaccination among Swedish high school students. Int J STD AIDS. 2009;20(2):102-7. http://dx.doi.org/10.1258/ijsa.2008.008200

13. Pineda EB, Alvarado EL, Canales FH. Metodologia de la investigacion: Manual para el desarrollo de personal de salud. Washington: Organizacion Panamericana de la Salud; 1994; p.184-189.

14. Instituto Brasileiro de Geografia e Estatística (IBGE) [Internet]. Série estudos e pesquisas: estatísticas de empreendedorismo 2012. Disponivel em: http://www.ibge.gov.br/estadosat/temas.php?sigla=sp\&tema=est_ empreendedorismo2012. Acesso em: 4 set. 2015.

15. Sait $\mathrm{KH}$. Attitudes, knowledge, and pratices in relation to cervical cancer and its screening among women in Saudi Arabia. Saudi Med J. 2009;30(9):1208-12.

16. Wash CD, Gera A, Shah M, Sharma A, Powell JE, Wilson S. Public knowledge and attitudes towards Human Papilloma Virus (HPV) vaccination. BMC Public Health. 2008;8:368. http://dx.doi.org/10.1186/1471-2458-8-368

17. Friedman AL, Shepeard H. Exploring the knowledge, attitudes and beliefs, and the communicating preferences of the general public regarding HPV: findings from CDC focus group research and implications for practice. Health Educ Behav. 2007;34(3):471-85. http://dx.doi.org/10.1177/1090198106292022

18. Panobianco MS, Lima ADF, Oliveira ISB, Gozzo TO. O conhecimento sobre o HPV entre adolescentes estudantes de graduação em enfermagem. Texto Contexto Enferm. 2013;22(1):201-7. http://dx.doi.org/10.1590/S0104-07072013000100024

19. Pineros M, Wiesner C, Cortes C, Trujillo LM. HPV vaccine introduction at the local level in a developing country: attitudes and criteria among key actors. Cad Saúde Pública. 2010;26(5):900-8. http://dx.doi.org/10.1590/S0102-311X2010000500012

20. Morales-Campos DY, Markam CM, Peskin MF, Fernandez ME. Hispanic mothers' and high school girls'perceptions of cervical cancer, human papilloma virus, and human papilloma virus vaccine. J Adolesc Health. 2013;52(5 Suppl):S69-75. http://dc.doi.org/10.1016/j.jadohealth.2012.09.020

21. Stephens DP, Thomas TL. Cultural values influencing immigrant Haitian mothers'attitudes toward human papillomavirus vaccination for daughters. J Black Psychol. 2013;39(2):156-68. http://dx.doi.org/10.1177/0095798412461807

(c) 2016 Pereira et al. Este é um artigo de acesso aberto distribuído nos termos de licença Creative Commons 